Original Article

\title{
Halogenated flame retardants in atmospheric particles from a North African coastal city (Bizerte, Tunisia): Pollution characteristics and human exposure
}

\author{
Badreddine Barhoumi ${ }^{\mathrm{a}, \mathrm{b}}$, Marc Tedetti ${ }^{\mathrm{c}}$, Andrea Peris ${ }^{\mathrm{b}}$, Catherine Guigue ${ }^{\mathrm{c}}$, \\ Òscar Aznar-Alemany ${ }^{\mathrm{b}}$, Soufiane Touil ${ }^{\mathrm{a}}$, Mohamed Ridha Driss ${ }^{\mathrm{a}}$, Ethel Eljarrat ${ }^{\mathrm{b}, *}$ \\ ${ }^{a}$ Laboratory of Hetero-Organic Compounds and Nanostructured Materials (LR18ES11), Department of Chemistry, Faculty of Sciences of Bizerte, University of Carthage, \\ 7021, Zarzouna, Tunisia \\ ${ }^{\mathrm{b}}$ Water, Environmental and Food Chemistry, Department of Environmental Chemistry, IDAEA-CSIC, Jordi Girona 18-26, 08034, Barcelona, Spain \\ ${ }^{\mathrm{c}}$ Aix Marseille Univ., Université de Toulon, CNRS, IRD, MIO UM 110, 13288, Marseille, France
}

\section{A R T I C L E I N F O}

\section{Keywords:}

Atmospheric particles

North Africa

Halogenated flame retardants

Methoxylated bromodiphenyl ethers

Dry deposition

Human exposure

\begin{abstract}
A B S T R A C T
In the present study, atmospheric particle samples were collected between September 2015 and February 2016 from Bizerte city (Tunisia) to investigate the occurrence, potential sources and impacts of a range of flame retardants (FRs), including hexabromocyclododecane diastereoisomers (HBCDDs), new halogenated flame retardants (NHFRs), as well as methoxylated polybrominated diphenyl ethers (MeO-BDEs). Among 19 examined compounds, 9 congeners ( $\alpha$-HBCDD, $\beta$-HBCDD, $\gamma$-HBCDD, HBB, DBDPE, syn-DP, anti-DP, 2 '-MeO-BDE-68 and 6 MeO-BDE-47) were detected in atmospheric particles at different levels and frequencies. Overall, the average concentration of NHFRs $\left(1.53 \mathrm{pg} \mathrm{m}^{-3}\right)$ was 1.5 and 51 folds higher than that of HBCDDs $\left(1.04 \mathrm{pg} \mathrm{m}^{-3}\right)$ and MeO-BDEs $\left(0.03 \mathrm{pg} \mathrm{m}^{-3}\right)$, respectively. By comparison with other areas of the world, NHFRs and HBCDDs in Bizerte were at medium pollution level, while MeO-BDEs were at lower levels. No significant correlations were found between NHFR, HBCDD and MeO-BDE concentrations, suggesting different sources related on one hand to the biogenic origin of MeO-BDE, and on the other hand to various types and utilisations of imported NHFR- and HBCDD-containing products, as Tunisia does not manufacture FRs. DP and HBCDD diastereoisomer profiles appeared to be divergent from their commercial products, pointing out that a complex degradation or stereoselective transformation processes occurring in ambient air around Bizerte city. The estimated daily human exposure dose (DED) to particle-bound HBCDDs, NHFRs and MeO-BDEs via outdoor air inhalation was generally at low levels. Hence, this study reports for the first time the occurrence and potential impact of HBCDDs, NHFRs and MeO-BDEs in atmospheric particles from North Africa.
\end{abstract}

\section{Introduction}

Flame retardants (FRs) include a diverse group of chemicals, which are added to consumer and industrial products, such as furnitures, electronic and electrical equipments, textiles, plastics, antifoaming agents, hydraulic fluids, construction materials, to prevent and minimise fire hazards (Alaee et al., 2003; Covaci et al., 2011; Chen et al., 2019). Polybrominated diphenyl ethers (PBDEs), as well as 1,2,5,6,9,10-hexabromocyclododecane diastereosomers (HBCDDs) (used mainly in building insulation) and tetrabromobisphenol A (TBBPA) have historically been the most widely used brominated flameretardants (BFRs) (Covaci et al., 2011; UNEP, 2015; Rauert et al., 2018). However, PBDEs and HBCDDs have been banned worldwide and added to the Stockholm Convention on Persistent Organic Pollutants (POPs) due to their persistence, bioaccumulation, and toxicity (Renner, 2004). Since then, a variety of new halogenated flame retardants (NHFRs) have been introduced as replacements. For example, the commercial Penta- and Octa-BDE formulations were primarily replaced by firemaster 550 and 1,2-bis (2,4,6-tribromophenoxy) ethane (BTBPE), and Deca-BDE formulation by decabromodiphenylethane (DBDPE) (Covaci et al., 2011). In addition, Dechlorane Plus (DP), a nonregulated, highly chlorinated FR, was suggested by the European Union as a possible replacement for the insecticide Mirex (Hoh et al., 2006) and Deca-BDE formulation (Meire et al., 2012). A few monocyclic aromatic compounds, with lower production volumes, such as pentabromoethyl benzene (PBEB) and hexabromobenzene (HBB), have 
also found new FR applications during this "FR revolution" (Ma et al., 2013). Large amounts of these NHFRs have been produced with growing annual demands due to the rapid economic development. Generally, they are used as additives rather than chemically bonded to the product matrix, which facilitates their release into the environment (Ali et al., 2016). As a result, NHFRs are consistently detected in different environmental media (Guerra et al., 2009; Zhao et al., 2013; Mekni et al., 2019; Reche et al., 2019). They are also detected regularly in Arctic (Liu et al., 2017; Vorkamp et al., 2015) and Antarctic (AznarAlemany et al., 2019a), indicating their potential to undergo long-range atmospheric transport. Although there are limited data about most NHFRs, especially production volumes, usages, toxicity, and physicalchemical properties, many of them show properties of persistency and toxicity (hormonal disruption, reproductive effects) leading to concerns over environmental levels (Abdelouahab et al., 2011; Zhang et al., 2016; Li et al., 2017).

Methoxylated brominated diphenyl ethers (MeO-BDEs), which are structurally related to PBDEs, may be transformation products of the latter (Zeng et al., 2008) or of natural (marine) origin, produced by sponges, mollusks, cyanobacteria and algae (Yu et al., 2013). MeOBDEs have gained attention in recent years because they have toxic properties (effect on mRNA abundance of steroidogenic enzymes in the H295R cell line) and display a greater biomagnification potential than PBDEs in aquatic food webs (He et al., 2008; Wiseman et al., 2011).

There is no record of FR production in African countries and, therefore, the possible sources of these pollutants in the air are assumed to be the release from imported FR-containing products and the longrange atmospheric transport. Electrical and electronic e-waste recycling coupled with poor disposal techniques (such as open burning and dumping at poorly or non-constructed landfill sites, or even in surface water bodies) has demonstrated to be an important emission source of FRs in Africa (Robinson, 2009; Schluep et al., 2011; Katima et al., 2017). According to Baldé et al. (2014) the total electrical and electronic waste equipment generation in Africa was 1.9 Mt in 2014.

Africa is one of the least studied continents in the world with respect to air quality (Laakso et al., 2007). Previous works in the atmosphere of North Africa have been focused on PBDEs and organophosphate ester (OPE) flame retardants and plasticizers (Castro-Jiménez et al., 2017; Castro-Jiménez and Sempéré, 2018). However, until now, there have been no published studies on halogenated FRs (HFRs), i.e., NHFRs, HBCDDs and MeO-BDEs in North Africa atmosphere. Hence, the objectives of this study were first to investigate the occurrence and pollution levels of HFRs and MeO-BDEs in atmospheric particles from Bizerte (Tunisia), a coastal, industrial-port city of North Africa. Secondly, to assess their potential sources and make a comparison with the levels of regulated PBDEs, and thirdly, to estimate their atmospheric dry deposition and human exposure risk. To our knowledge, this is the first report of atmospheric concentrations of MeO-BDEs for the entire African continent.

\section{Materials and methods}

\subsection{Atmospheric particle sampling}

Seventeen atmospheric particle samples were collected from September 2015 to February 2016 on the roof of the Faculty of Sciences of Bizerte $\left(37^{\circ} 16^{\prime} 0.5802^{\prime \prime} \mathrm{N}, 9^{\circ} 52^{\prime} 49.875^{\prime \prime} \mathrm{E}\right.$; $8 \mathrm{~m}$ above ground level), $\sim 1 \mathrm{~km}$ far from the Bizerte city center, between the Mediterranean Sea and the Bizerte Lagoon (Fig. S1 in the supplementary information (SI)). Detailed descriptions of the sampling site, sample collection and pretreatment procedures have been given elsewhere (Barhoumi et al., 2018). Briefly, Bizerte is a medium-sized city $(\sim 127,000$ inhabitants), with a humid climate and economic activity focused mainly on agriculture, fishing and operations of light and heavy industries (Barhoumi et al., 2018), inducing a considerable anthropogenic pressure. A high volume air sampler (Tisch Environmental Inc.,
$\mathrm{OH}$, USA) equipped with a precombusted $\left(450{ }^{\circ} \mathrm{C}, 6 \mathrm{~h}\right)$ quartz fiber filters (QFFs) (Whatman QMA grade, $20.3 \times 25.4 \mathrm{~cm}$ ) was used to collect samples for $48 \mathrm{~h}$ at an average flow rate of $0.66 \mathrm{~m}^{3} \mathrm{~min}^{-1}$, resulting in a total sample volume of $\sim 1900 \mathrm{~m}^{3}$ for each sample.

After collection, QFFs were individually wrapped in a clean aluminum foil, transported to the laboratory and stored in a freezer at $-20{ }^{\circ} \mathrm{C}$ before processing. They were conditioned in a desiccator $\left(25^{\circ} \mathrm{C}\right.$ ) for $24 \mathrm{~h}$, weighted using a microbalance, and then cut into two equal parts. One half was used for HFR and MeO-BDE analysis and the other half for the determination of total suspended particles (TSP), organic carbon (OC) and organic nitrogen (ON). Details regarding the sampling dates, meteorological conditions and collected air volumes, as well as TSP, OC and ON concentrations for each sample, are given in the SI (Table S1).

\subsection{Analytical procedures}

Details on analytical procedures (chemicals, extraction and instrumental analysis) are presented in the SI (Text S1). Briefly, QFF filters were cut into small pieces, spiked with a multi-standard mixture containing internal standards for PBDEs $\left({ }^{13} \mathrm{C}-\mathrm{BDE}-28,-47,-99,-100\right.$, $-153,-154,-183$ and -209$)$, dechloranes $\left({ }^{13} \mathrm{C}-\right.$ syn-DP), and hexabromocyclododecane ( $\mathrm{d}_{18} \alpha$-HBCDD), and extracted using a fully automated accelerated solvent extraction system (ASE 350). The extracts were then purified using solid phase extraction (SPE), and depending on the analytes, the analysis of compounds was performed using:

- A liquid chromatography coupled to tandem mass spectrometry (LCMS-MS) using electrospray ionisation (ESI), for HBCDDs.

- A gas chromatography coupled to tandem mass spectrometry (GC-MS-MS) working with negative ion chemical ionisation (NICI), for dechloranes.

- A gas chromatography coupled to mass spectrometry working with negative ion chemical ionisation (GC-NCI-MS), for DBDPE.

- And an agilent 7890 gas chromatography coupled to an Agilent $7000 \mathrm{~A}$ GC/MS triple quadrupole working with electron ionisation (EI) (GC-EI-MS-MS), for PBEB, HBB and MeO-BDEs.

The concentrations of TSP in the QFFs were determined according to Barhoumi et al. (2018) while OC and ON concentrations were determined by high temperature combustion ( $\mathrm{CHN}$ analyzer) (Raimbault et al., 2008).

\subsection{Quality assurance/quality control $(Q A / Q C)$}

QA/QC was conducted by analysing field and laboratory blanks, calibrations of the high volume air sampler, and evaluation of the analytical performance of the instruments, which includes reproducibility, detection limits and standard spiked recoveries. Three field blanks were collected for the whole sampling period by placing a QFF in the air sampler and immediately removing without drawing air through the sampler. Laboratory and field blanks were processed in the same way as the samples to determine the contamination introduced during extraction and clean-up, and by handling, shipping and storage, respectively. Laboratory blanks were included with each batch of 5 samples. All target compounds measured in this study were detected in the blanks (field and laboratory blanks) with amounts ranging from 0.07 to $1.17 \mathrm{pg}$ (Table S3). The air sampler was regularly calibrated (each month) following the manufacturer's manual (Tisch Environmental, $\mathrm{HIGH} \mathrm{VOL}^{+}$). Multilevel calibration curves, covering the whole concentration ranges found in the samples, were used to quantify the analytes, and $\mathrm{R}^{2}$ values $>0.95$ were found for all of the analytes (Table S3). Quantification was carried out by isotopic dilution method based on the use of isotopically labeled standards. Table S2 shows the target compounds analysed in this study with each corresponding internal standard. A blank clean QFF was spiked with $50 \mu \mathrm{L}$ of standards 
(100 pg/ $\mu \mathrm{L}$ for each HFR and $50 \mathrm{pg} / \mu \mathrm{L}$ for each MeO-BDEs), and processed as real samples. Recoveries from spiked QFF were in the range of $54-104 \%$ and $61-81 \%$ for HFRs and MeO-BDEs, respectively, being always within the range established as acceptable for isotopic dilution methods (40-120\%). Reproducibility of the method was also satisfactory with relative standard deviations (RSD) $<20 \%$. Method detection limits (MDLs) defined as mean blank value $+3 \times$ standard deviation (SD) (considering an average sampled air volume of $806 \mathrm{~m}^{3}$ ), ranged from 0.1 to $1.5 \mathrm{fg} \mathrm{m}^{-3}$ (Table S3). For compounds that were not detected in blanks, instrument detection limits (IDLs), determined as a signal-to-noise ratio $(\mathrm{S} / \mathrm{N})$ of 3 , were substituted. If the concentration of a given compound in a sample was below its MDL/IDL, thus this compound was considered as not dectected in the sample, and was assumed zero for deriving sums and calculating fluxes. All data reported here were blank corrected.

\subsection{Data handling}

The targeted compounds analysed in this study were classified into two groups, the HFRs (PBEB, HBB, DBDPE, Dechlorane 602 (DDC-DBF), Dechlorane 603 (DDC-Ant), Dechlorane 604 (HCTBPH), syn-DP, antiDP, $\alpha$-HBCDD, $\beta$-HBCDD, $\gamma$-HBCDD) and MeO-BDEs (5-MeO-BDE-47, 6MeO-BDE-47， 4'-MeO-BDE-49， 2'-MeO-BDE-68， 5'-MeO-BDE-99， 5'MeO-BDE-100, 4'-MeO-BDE-101 and 4'-MeO-BDE-103), defined as $\Sigma$ HFRs and $\Sigma$ MeO-BDEs, respectively. Among HFRs, eight compounds (PBEB, HBB, DBDPE, DDC-DBF, DDC-Ant, HCTBPH, syn-DP, anti-DP) named new halogenated flame retardants are defined as $\Sigma$ NHFRs (or NHFRs), and three compounds ( $\alpha$-HBCDD, $\beta$-HBCDD, $\gamma$-HBCDD) are defined as $\Sigma$ HBCDDs (or HBCDDs), which are considered as discontinued FRs. Dechlorane Plus represents the sum of syn-DP and antiDP, and is defined as $\Sigma$ DPs (or DPs).

Box-and-whisker plots and Spearman rank order correlations were performed using graph prism 5 software. Mann-Whitney nonparametric tests (U-tests), conducted with Stat-View 5.0, were used to compare the distributions of two groups. The significance level for the result was set at $\mathrm{p} \leq 0.05$. Principal component analysis (PCA) was performed using XLSTAT 2013.5.01.

The dry deposition fluxes ( $\mathrm{F} \mathrm{pg} \mathrm{m}^{-2}$ day $^{-1}$ ) of HFRs and MeO-BDEs associated with particles were calculated as follows:

$\mathrm{F}=\mathrm{V}_{\mathrm{d}} \times \mathrm{C}_{\mathrm{PM}}$

where $\mathrm{V}_{\mathrm{d}}$ is the deposition velocity and $\mathrm{C}_{\mathrm{PM}}$ is the volumetric concentration of HFRs and MeO-BDEs in atmospheric particles $\left(\mathrm{pg} \mathrm{m}^{-3}\right)$. $\mathrm{V}_{\mathrm{d}}$ is known to be variable, depending on particle size and meteorological conditions. There are no measured velocities available for these compounds for the Mediterranean Sea conditions. Based on recent works on the dry deposition of POPs and OPE (Castro-Jiménez et al., 2017; Barhoumi et al., 2018; Castro-Jiménez and Sempéré, 2018) we used in the present study a constant velocity of $0.2 \mathrm{~cm} \mathrm{~s}^{-1}$. The results from this calculation only provide indicative estimation of fluxes that should be eventually validated by experimental measurements.

The daily human exposure dose (DED, $\mathrm{pg} \mathrm{kg}^{-1} \mathrm{bw} \mathrm{day}{ }^{-1}$ ) to particle-bound HFRs and MeO-BDEs via outdoor air inhalation was calculated using Eq. (2) proposed by the U.S. Environmental Protection Agency (USEPA) Exposure Factor Handbook (USEPA, 2011):

$\mathrm{DED}=\mathrm{C} \times \mathrm{IR} \times \mathrm{ED} \times \mathrm{AF} / \mathrm{BW}$

where $\mathrm{C}_{\mathrm{PM}}$ is the measured concentration of particle-bound HFRs/MeOBDEs in each sample $\left(\mathrm{pg} \mathrm{m}^{-3}\right)$; IR is the inhalation rate $\left(\mathrm{m}^{3}\right.$ day $\left.{ }^{-1}\right)$; ED is the exposure duration per day $\left(\mathrm{h} \mathrm{day}^{-1}\right.$ ); $\mathrm{AF}$ is the absorption fraction (the inhalation fraction was assumed to be $100 \%$ bioavailable) and BW is the body weight of human $(\mathrm{kg})$. A mean daily inhalation rate of $16.0 \mathrm{~m}^{3}$ day $^{-1}$ was employed for adults and $7.6 \mathrm{~m}^{3}$ day $^{-1}$ for children (Zhang et al., 2019). It was assumed that a person spends $6 \mathrm{~h} /$ day in an outdoor environment (i.e., 1/4 of the day) (Deng et al., 2018). The average body weight was considered to be $60 \mathrm{~kg}$ for adults and $16 \mathrm{~kg}$

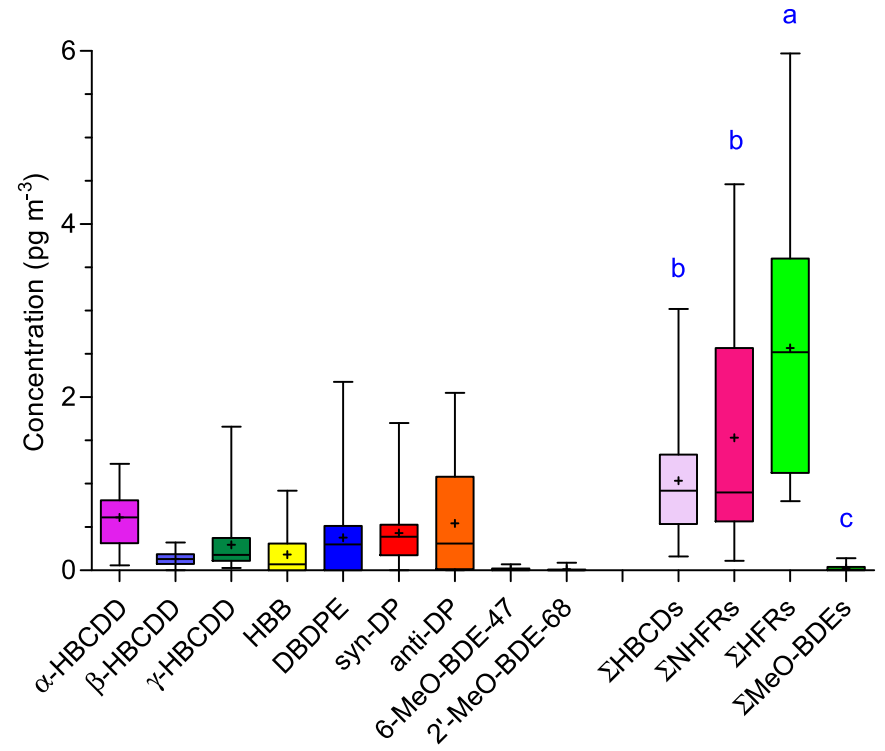

Fig. 1. Concentrations (pg m ${ }^{-3}$ ) of HBCDDs, NHFRs and MeO-BDEs in atmospheric particles of Bizerte city as shown in box-and-whisker plots across the whole sampling period (September 2015 to February 2016). Boxes represent the interquartile range, bound by the 75 th and 25 th percentiles. Line and cross markers indicate medians and averages, respectively, whereas error bars show minimum and maximum concentrations. Comparison between mean total concentrations ( $U$ test, $\mathrm{p}<0.05$ ) is shown; the concentration distributions sharing the same letter are not statistically different at $\mathrm{p}<0.05$.

for children (Liu et al., 2016; Deng et al., 2018).

\section{Results and discussion}

From a total 19 target analytes, 3 HBCDDs ( $\alpha$-HBCDD, $\beta$-HBCDD, $\gamma$ HBCDD), 4 NHFRs (HBB, DBDPE, syn-DP, anti-DP) and 2 MeO-BDEs ( 2 'MeO-BDE-68, 6-MeO-BDE-47) were detected in samples with detection frequency ranging between 94 and 100\% (Table S4). The concentrations of $\Sigma$ HFRs and $\Sigma \mathrm{MeO}$-BDEs ranged from 0.80 to $5.97 \mathrm{pg} \mathrm{m}^{-3}$ and from nq to $0.14 \mathrm{pg} \mathrm{m}^{-3}$, with a mean (median) of 2.57 (2.52) $\mathrm{pg} \mathrm{m}^{-3}$ and $0.03(0.01) \mathrm{pg} \mathrm{m}^{-3}$, respectively (Table S4, Fig. 1 and Fig. S2). Overall, the mean concentration of NHFRs was 1.5 and 51 times higher than that of HBCDDs and MeO-BDEs, respectively (Fig. 1).

\subsection{Concentrations and composition profiles}

\subsubsection{Hexabromocyclododecanes}

HBCDDs in air were largely particle-bound and rarely detected in the gas phase because of their low vapor pressure and high affinity for particles (Jo et al., 2017). In the present study, except for one sample for which $\beta$-HBCDD was not detected, the detection frequency of the three HBCDDs was $100 \%$ in all atmospheric particle samples (Table S4). The mean (median) concentrations of $\alpha$-, $\beta$-, and $\gamma$-HBCDD were 0.60 (0.61), $0.13(0.13)$, and $0.29(0.18) \mathrm{pg} \mathrm{m}^{-3}$, respectively (Table S4 and Fig. 1). $\Sigma$ HBCDDs ranged from 0.16 to $3.02 \mathrm{pg} \mathrm{m}^{-3}$ with a mean (median) of $1.04(0.92) \mathrm{pg} \mathrm{m}^{-3}$, which was comparable to the values from Guangzhou and Shenzhen, China, and Central Brno, Czech Republic (Okonski et al., 2014; Yu et al., 2008a; Zhu et al., 2018). Our concentrations were lower than those from Beijing, Shanghai (Zhabei) and Dalian in China, but much higher than those from North-East Greenland, Denmark and Stockholm, Sweden (Table 1) (Hu et al., 2011; Li et al., 2012, 2018; Newton et al., 2015; Vorkamp et al., 2015).

The HBCDD composition profile along the whole sampling period is shown in Fig. 2. Overall, $\alpha$ - and $\gamma$-HBCDDs were the most abundant diastereomers, contributing on average about 59 and $29 \%$ to the 


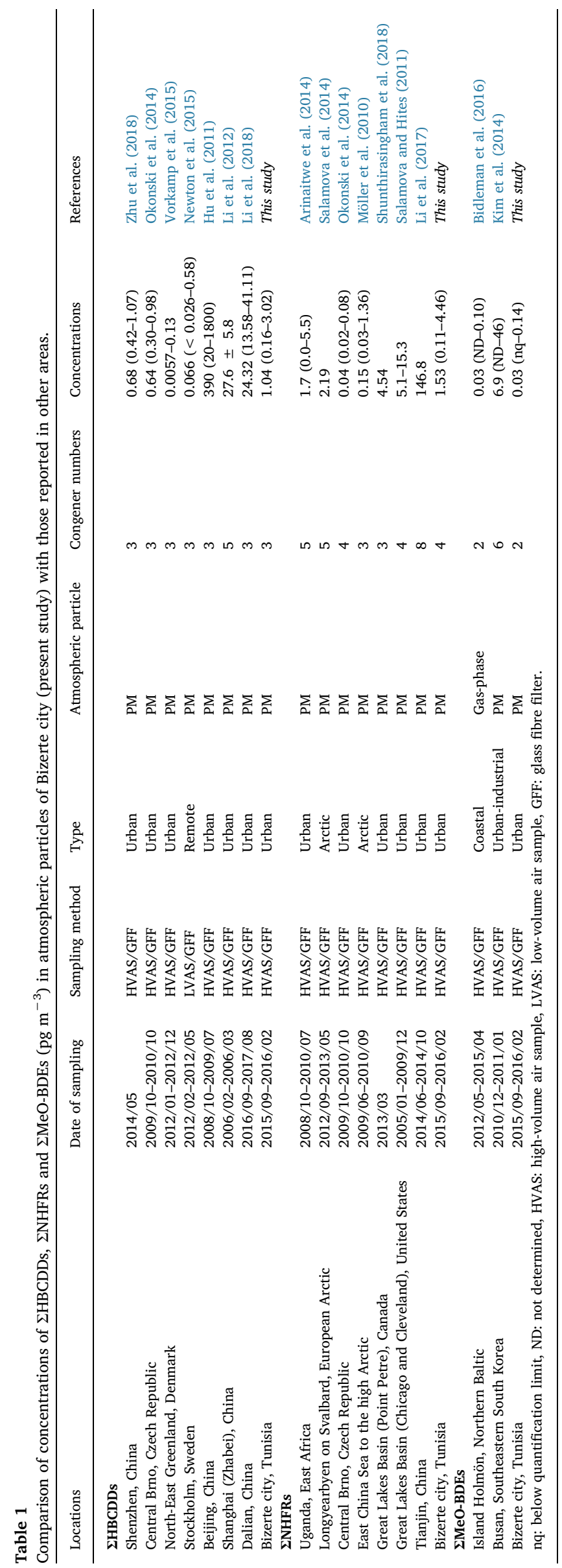

$\Sigma$ HBCDD concentrations, respectively. $\beta$-HBCDD was the less abundant with an average contribution of $\sim 13 \%$. In the HBCDD technical formulation, the diastereomer contributions is generally $75-89 \%$ for $\gamma$ HBCDD with $\alpha$ - and $\beta$-accounting for $10-13 \%$ and $1-12 \%$, respectively (Fig. 3) (Covaci et al., 2006). Therefore, the composition profile observed here is clearly divergent from that of the initial technical formulation (Fig. 3). The diastereomers can undergo thermal rearrangements at temperatures above $160{ }^{\circ} \mathrm{C}$, resulting in profiles containing 78\% $\alpha$-HBCDD, 13\% $\beta$-HBCDD and 9\% $\gamma$-HBCDD (Covaci et al., 2006), which is more in line with the profile detected in Bizerte city (Fig. 3). Other authors (Newton et al., 2015; Drage et al., 2016; Rauert et al., 2018; Li et al., 2018; Yu et al., 2008a; Zhu et al., 2018) also found a similar profile with a predominance of $\alpha$-HBCDD. By contrast, Abdallah et al. (2008), Hu et al. (2011) and Hoh and Hites (2005) reported higher $\gamma$-HBCDD contributions to $\Sigma$ HBCDD levels in atmospheric samples from Birmingham (UK), Beijing (China) and Chicago (US) (89, 61 and $83 \%$, respectively) (Fig. 3). In our study, the average ratio of the air concentration of $\alpha$-HBCDD to $\gamma$-HBCDD (2.74) was comparable with that of decorative polystyrene $(\alpha / \gamma=2.1)$, but were not similar to those of the commercial mixtures, where the $\gamma$ isomer is dominant, or construction polystyrene $(\alpha / \gamma=0.07)$ (Kukučka et al., 2013). These results suggest that thermal isomer conversion and photodegradation could be an explanation for the higher abundances of $\alpha$-HBCDD encountered in the Bizerte urban air (Koppen et al., 2008; Covaci et al., 2011; Okonski et al., 2014), which is also supported by the significant positive correlation $(\mathrm{p}<0.001)$ between the concentrations of $\gamma$ HBCDD and $\alpha$-HBCDD or $\beta$-HBCDD (Table S5).

According to the Bizerte climatic conditions, the sampling period (autumn and winter) is considered as cold and humid (Barhoumi et al., 2018). Thereby, no clear seasonal differences or correlations with temperature were observed for $\Sigma$ HBCDD concentrations (Fig. S2A and Table S5), which was consistent with the results reported by Drage et al. (2016) in Birmingham (UK) air.

\subsubsection{Alternative/new FRs}

From 8 NHFRs analysed, only 4 compounds were detected in all samples with the detection frequency of $100 \%$ (Table S4). $\Sigma$ NHFRs ranged from 0.11 to $4.46 \mathrm{pg} \mathrm{m}^{-3}$ with a mean (median) concentrations of $1.53(0.90) \mathrm{pg} \mathrm{m}^{-3}$. anti-/syn-DP were the most predominating compounds (64\% together, 0.54 and $0.43 \mathrm{pg} \mathrm{m}^{-3}$, respectively) followed by DBDPE $\left(25 \%, 0.38 \mathrm{pg} \mathrm{m}^{-3}\right)$ and HBB $\left(12 \%, 0.18 \mathrm{pg} \mathrm{m}^{-3}\right)$ (Table S4, Figs. 1 and 2). In comparison to other studies, the average level of HBB reported here is close to that observed by Saini et al. (2019) in Toronto, Canada (0.24 $\mathrm{pg} \mathrm{m}^{-3}$ ), Khairy and Lohmann (2018) in Alexandria, Egypt (0.92 $\mathrm{pg} \mathrm{m}^{-3}$ ) and by Ma et al. (2013) in Chicago and Cleveland, US (0.67 and $0.81 \mathrm{pg} \mathrm{m}^{-3}$, respectively). However, it was significantly lower than that reported by Kurt-Karakus et al. (2017) in Istanbul, Turkey ( $510 \mathrm{pg} \mathrm{m}^{-3}$ ). DBDPE concentrations were similar to those measured in Eagle Harbor $\left(1.0 \mathrm{pg} \mathrm{m}^{-3}\right.$ ) (Venier and Hites, 2008) and lower than that detected in Southern China (158 $\mathrm{pg} \mathrm{m}^{-3}$ ) (Tian et al., 2011). The mean DP concentrations in this study were similar to those observed in the atmosphere of the Canadian High Arctic $\left(<0.05-2.1 \mathrm{pg} \mathrm{m}^{-3}\right.$ ) (Möller et al., 2010), Spain $\left(0.7 \pm 0.5 \mathrm{pg} \mathrm{m}^{-3}\right.$ ) (Reche et al., 2019) and in samples from Beijing $\left(2.0 \pm 3.9 \mathrm{pg} \mathrm{m}^{-3}\right.$ ) and Dalian ( $3 \pm 6 \mathrm{pg} \mathrm{m}^{-3}$ ) (Yu et al., 2011), but up to 10 times lower than those measured in air samples from 97 Chinese sites $\left(15 \pm 15 \mathrm{pg} \mathrm{m}^{-3}\right.$ ) (Ren et al., 2008). As shown in Table 1, the $\Sigma$ NHFR concentrations measured in this study generally fell within the lowermiddle ranges of the levels reported in previous studies around the world.

The isomeric composition of DPs is a useful tool to track the transport and fate of these chemicals. The fractional abundance $\left(f_{a n t i}\right)$ is defined as the amount of anti-DP divided by the total amount of both DP isomers. The $f_{\text {anti }}$ values observed here ranged from nq to 0.79 , with a mean of $0.41 \pm 0.28$ (Fig. S3), which is lower than those in the commercial DP products Anpon and OxyChem (0.64-0.80 and 0.60, 

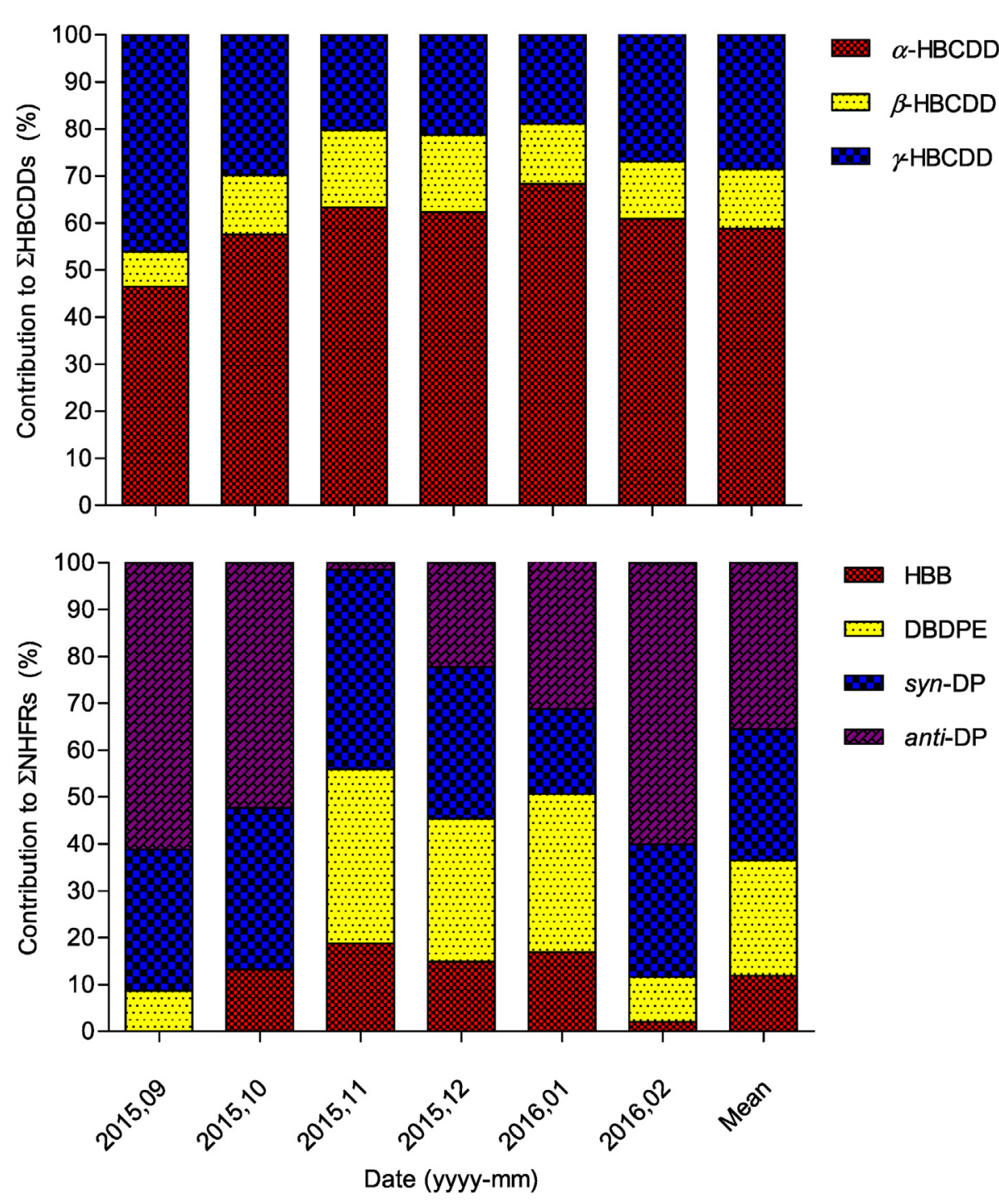

Fig. 2. Composition profiles of HBCDDs and NHFRs in atmospheric particle of Bizerte city from September 2015 to February 2016.

respectively) (Wang et al., 2010). Considering the preferential atmospheric photodegradation of the anti-isomer and its isomerisation over the $s y n$-isomer, our $f_{\text {anti }}$ values may reflect degradation/transformation processes that may occurr during long- or short-range atmospheric transport (Möller et al., 2010; Yang et al., 2011).

Temporal variations of the $\Sigma$ NHFR concentrations are showed in Fig. S2B. Like $\Sigma$ HBCDDs, there were no notable seasonal (autumn versus winter) differences in levels of NHFRs. The highest $\Sigma$ NHFR concentrations, recorded in December 2015 and January 2016, did not co-occur with HBCDD peak (September 2015). This emphasises differences in emission patterns and possibly source regions for NHFRs and HBCDDs (Vorkamp et al., 2015).

\subsubsection{Methoxylated bromodiphenyl ethers}

Two of the eight measured MeO-BDEs were detected in all atmospheric particle samples of Bizerte city, with concentrations ranging from nq to $0.14 \mathrm{pg} \mathrm{m}^{-3}$ and a mean (median) of $0.03(0.01) \mathrm{pg} \mathrm{m}^{-3}$ (Table S4, Fig. 1 and Fig. S2D). In the same region, Ben Ameur et al. (2013), El Megdiche et al. (2017) and Mekni et al. (2019) have also detected 6-MeO-BDE-47 and 2'-MeO-BDE-68 are the most abundant MeO-BDEs in fishes (Solea solea), clams (Ruditapes decussatus) and sea urchins (Paracentrotus lividus) from the Bizerte Lagoon. These two compounds have also been the most frequently observed MeO-BDEs in marine environment (Barón et al., 2015; Aznar-Alemany et al., 2019b;
Routti et al., 2009), where those have been found to be naturally produced by the metabolic activities of marine sponges, bacteria or red algae in the presence of bromine, bromoperoxidase and hydrogen peroxide (Malmvarn et al., 2005; Nomiyama et al., 2011). Interestingly, in the Baltic region, the highest levels of MeO-BDEs have been recorded in summer, and the lowest in winter (Löfstrand et al., 2011; Dahlberg et al., 2016), leading to the assumption that phytoplanktonic production is the main source of MeO-BDEs (Löfstrand et al., 2011). Barhoumi et al. (2018) also found that the highest levels of the biogenic $n$-alkanes in the atmospheric particle samples of Bizerte city were observed in spring and summer due to the algae bloom occurring at this period in Bizerte Lagoon (Grami et al., 2008). In the same way, the MeO-BDE peak in September 2015 (Fig. S2D) could be related to phytoplankton activity occurring in the Bizerte Lagoon and/or marine coastal waters in late summer. Since our samples were obtained in fall and winter, we may assume that higher levels of MeO-BDEs could be detected during spring and summer, which warrants further investigations.

Data on MeO-BDEs, especially in the atmosphere, are extremely limited. Kim et al. (2014) reported a higher mean concentration (6.9 $\mathrm{pg} \mathrm{m}^{-3}$ ) in atmospheric particle samples from Busan (South Korea). On the other side, Bidleman et al. (2016) determined comparable levels (mean of $0.03 \mathrm{pg} \mathrm{m}^{-3}$ ) in Island Holmön (Northern Baltic) (Table 1). It is worth noting that the comparison of the HBCDD, NHFR and $\mathrm{MeO}-\mathrm{BDE}$ concentrations recorded in this study with those reported 


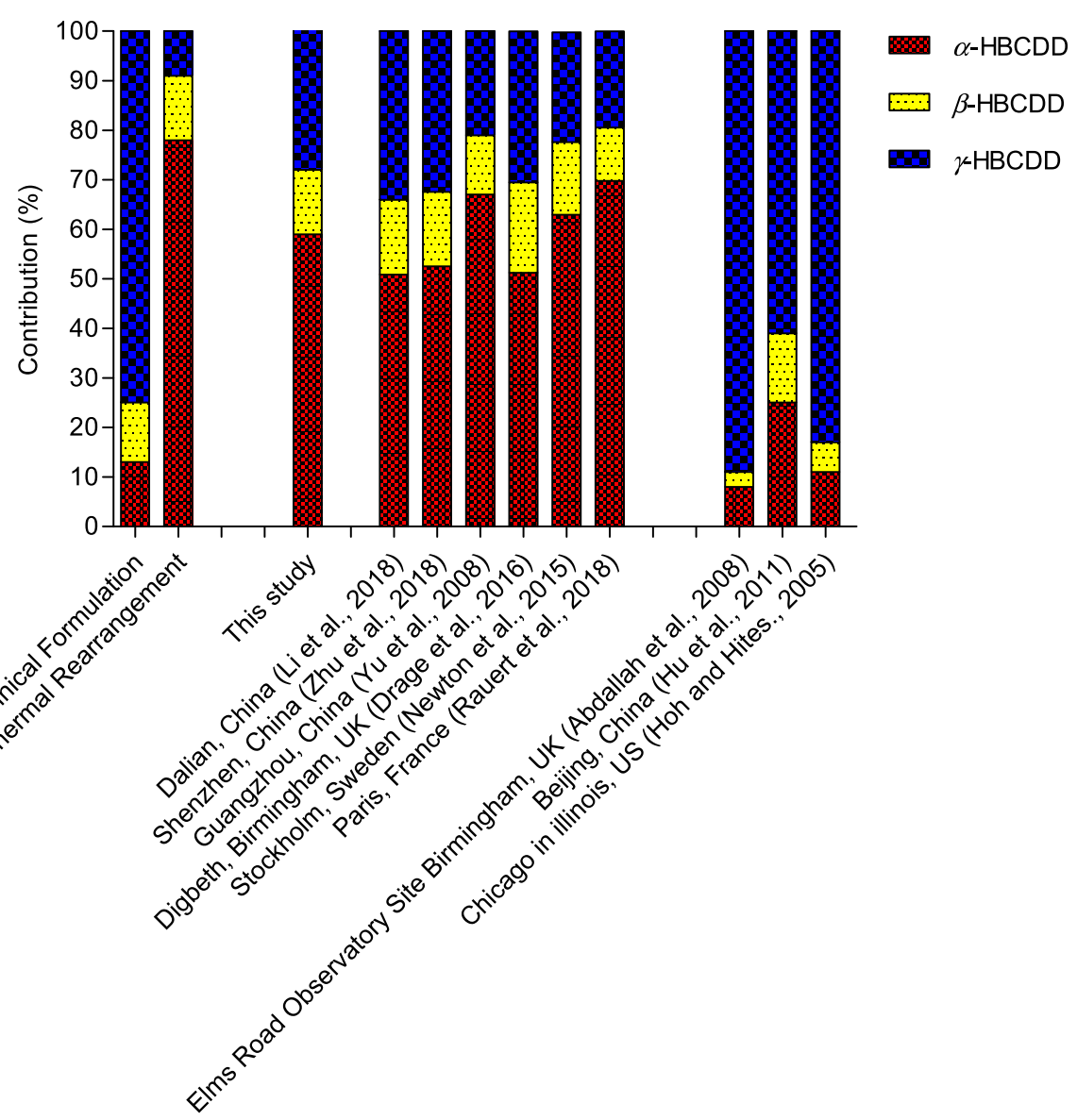

Fig. 3. Comparison between the HBCDD diastereomer profiles reported in Bizerte city (this work) with those of technical formulation, thermal rearrangements and other atmospheric studies.

in literature must be taken with caution, as the meteorological conditions, the number of samples collected, and the number of compounds analysed may not be the same.

\subsection{Influence of air mass origin and meteorological parameters}

The PCA loading and score plots of the whole dataset are shown in Fig. 4. The target chemicals were clearly separated into three clusters:
HBCDDs were clustered together in top right corner of the plot, while NHFRs and MeO-BDEs were clustered in lower-right and upper-left of the plot, respectively (Fig. 4a). This may suggest that HBCDD, NHFR and $\mathrm{MeO}-\mathrm{BDE}$ individuals originated from different sources or have different fates (Deng et al., 2018). This result is consistent with that of the Spearman's rank correlation (Table S5). The weak correlation between HBCDDs, NHFRs and MeO-BDEs was expected due to their various physical-chemical properties and applications. The strong
(A)

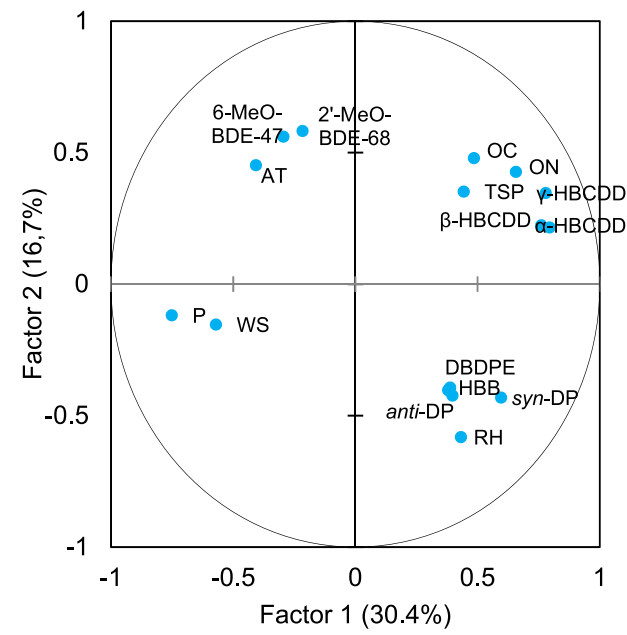

(B)

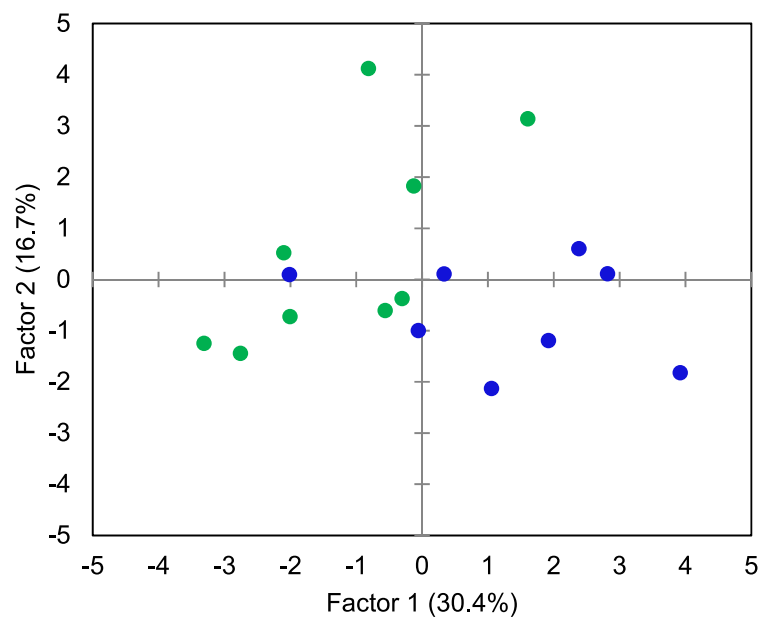

Fig. 4. Spearman principal component analysis loading (A) and scores (B) plots for the first two components of TSP, OC, ON, HBCDDs, NHFRs, MeO-BDEs and meteorological (AT, WS, RH, P) variables for the atmospheric particle samples of Bizerte city. Green and blue colors indicate autumn and winter seasons, respectively. 
significant correlation between syn-DP and anti-DP $(\mathrm{r}=0.777$, $\mathrm{p}<0.001)$ and between HBCDD diastereoisomers $(\mathrm{r}=0.820-0.870$, $\mathrm{p}<0.001$ ) can be explained by their similar sources, which is obvious given their similar use, origin and chemical properties (Saini et al., 2019). No evident temporal separation was observed from PCA score plots for most of samples (Fig. 4b). Relatively high scores of PC1 were found in some samples collected in autumn and winter, indicating that HBCDDs and NHFRs were dominant during both seasons.

The influence of each meteorological parameter on the levels of HBCDDs, NHFRs and MeO-BDEs measured in this study was assessed. Individual HBCDDs and NHFRs exhibited negative correlations with ambient temperature (AT) and precipitation (P), and positive correlations with relative humidity (RH) (Table S5 and Fig. 4). Inversely, MeOBDEs had positive correlations with AT, and significant negative correlations with RH, suggesting that HBCDDs and NHFRs had high affinity for particles, while MeO-BDEs had high affinity to gaseous phase. Similar results were highlighted by Jo et al. (2017) and Löfstrand et al. (2011). Masiol et al. (2013) shows that low temperatures may stimulate the transfer of pollutants from the gaseous to particulate phase, and inversely, while RH and precipitation promote pollutant condensation on particulate matter and deposition. Some positive and negative correlations appeared between individual HBCDDs/NHFRs/MeO-BDEs, and TSP, OC and ON (Table S5). This indicates that the levels of HBCDDs, NHFRs and MeO-BDEs in the Bizerte atmosphere were not driven by a single meteorological parameter, but by the combined effect of several meteorological conditions.

To investigate the influence of local atmospheric transport on atmospheric concentrations of HFRs and MeO-BDEs in Bizerte city, wind sector was applied (Fig. S4). As shown in Fig. S4, the dominant wind directions were from the West-North-West (WNW) and the North-West (NW) in autumn, and the South-East (SE) in winter. This suggests that local emissions from downtown Bizerte (high urbanisation), lead and cement factories, located NW of the site, and from Zarzouna city (municipal waste incineration) and Menzel Jemil city (mechanic and electronic factories, tire, plastic and textile industries), located SE of the site, are the most likely to influence the pollutant levels observed here. By using the NOAA HYSPLIT Backward Trajectory Model, Barhoumi et al. (2018) found that the influence of inter-continental atmospheric transport was minor in the same area and same period, since the air masses reaching the sampling site were of oceanic origin with limited passage through the European continent. Indeed, the clean nature of the oceanic air masses and high wind speeds above the Mediterranean Sea can disperse pollutants before they reach the sampling site. The negative coorelations between wind speed (WS) and all individual HFRs and MeO-BDEs concentrations (Table S5), suggested the predominance of local sources, since strong winds flush pollutants out of the study area whereas weak winds allow pollutants to accumulate over time (Barhoumi et al., 2018).

The presence of HBCDDs in the air can be attributed to a variety of sources including, plastics, installed insulation boards in buildings, textiles, and municipal and hospital waste incineration (Lassen et al., 1999; Morf et al., 2008). DPs is mainly used for coating electrical wires and cables, connectors in computers, and plastic decoration materials (Qiu et al., 2007), which are widely used in urban areas. HBB is used mainly as an additive FR in papers, wood, textiles, electronics and plastics (Li et al., 2017). DBDPE is added to various polymeric materials, such as high-impact polystyrene, polypropylene and acrylonitrile butadiene styrene (ABS), which is used mainly in televisions, computers and cable boxes (Covaci et al., 2011; Pei, 2014). In Tunisia, there is no FR manufacturing plant. Therefore, based on these applications, we assumed that air transportation from local sources and release from FRcontaining products are the most likely sources of particulate atmospheric HFRs in Bizerte city.

\subsection{Comparison of atmospheric PBDE and NHFR concentrations}

DBDPE was introduced to the market as alternative/replacement for the discontinued BDE-209 (Kierkegaard et al., 2004). In order to evaluate the PBDE response to their bans by the EU, we compared DBDPE concentrations measured in this study with those of BDE-209 measured by Castro-Jiménez et al. (2017) in atmospheric particles collected from the same area and same period (Fig. S5). BDE-209 concentration was significantly higher $(U$ test, $\mathrm{p}<0.05)$ than DBDPE concentration $(10$ times higher on average), and no significant correlation was found between these two compounds, pointing out that the use of DBDPE was still low in Bizerte city during the sampling period (2015-2016) compared to the use of BDE-209. Mekni et al. (2019) found a predominance of DBDPE over BDE-209 (BDE-209/DBDPE: < MDL-0.85) in sediment samples collected from the Bizerte Lagoon. The strongest degradation and debromination of BDE-209 in sediment relative to atmosphere can explain the predominance of DBDPE in sediments (Raff and Hites, 2007; Demirtepe and Imamoglu, 2019).

\subsection{Estimation of particle dry deposition fluxes and human exposure via inhalation}

Dry particle deposition is a continuous mechanism of the input of particle-bound contaminants into the global ocean during periods without precipitation (Dachs et al., 2002). For the study period, the dry deposition fluxes of $\Sigma$ HBCDDs, $\Sigma$ NHFRs and $\Sigma$ MeO-BDEs ranged from 28.4 to $521 \mathrm{pg} \mathrm{m}^{-2}$ day $^{-1}, 18.5-771 \mathrm{pg} \mathrm{m}^{-2}$ day $^{-1}$ and from nq to $24.5 \mathrm{pg} \mathrm{m}^{-2} \mathrm{day}^{-1}$, with a mean (median) of 265 (155) $\mathrm{pg} \mathrm{m}^{-2} \mathrm{day}^{-1}$, 179 (158) $\mathrm{pg} \mathrm{m}^{-2}$ day $^{-1}$ and 5.01 (1.46) $\mathrm{pg} \mathrm{m}^{-2}$ day $^{-1}$, respectively (Fig. 5 and Table S6). Dry deposition fluxes of $\Sigma$ HBCDDs and $\Sigma$ NHFRs were slightly higher in winter than in autumn, while $\Sigma \mathrm{MeO}$-BDEs were slightly higher in autumn. The seasonal fluctuation can be explained by the different ambient concentrations, phytoplankton activities and meteorological conditions (i.e., relative humidity, wind speed, temperature, and atmospheric stability) (Tasdemir and Holsen, 2005; Löfstrand et al., 2011). Very limited data are available for comparison with the HBCDDs, NHFRs and MeO-BDEs deposition fluxes measured in this study. Atmospheric dry deposition fluxes of $\Sigma$ HBCDDs estimated in this work are similar to those reported in rural sites of Southern China (mean of $193 \mathrm{ng} \mathrm{m}^{-2} \mathrm{yr}^{-1}$ ) (Tian et al., 2011), but 12 times lower than those estimated in an urban site in central Brno, Czech Republic (mean of $2.1 \mathrm{ng} \mathrm{m}^{-2} \mathrm{day}^{-1}$ ) (Okonski et al., 2014). This may be due to

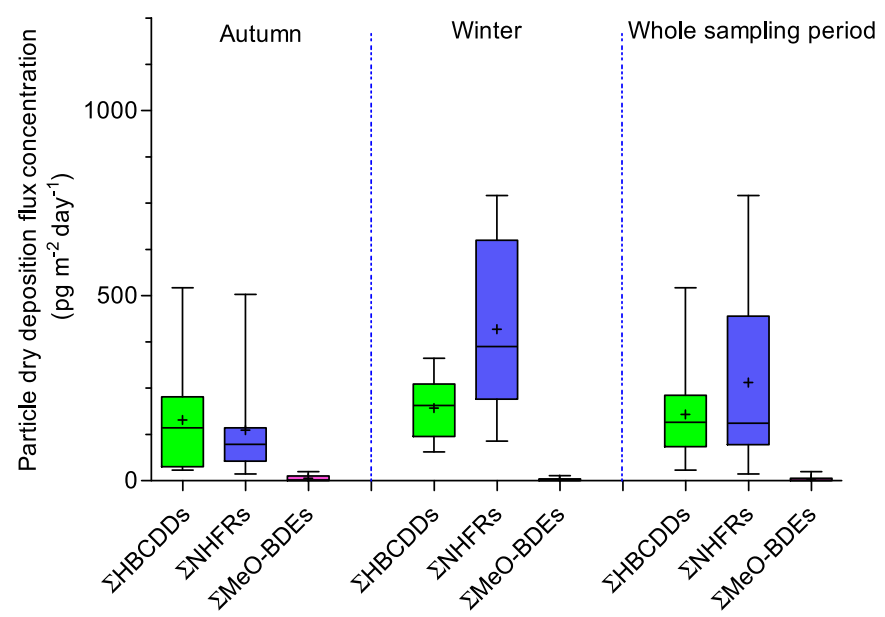

Fig. 5. Box-and-whisker plots of atmospheric particle dry deposition fluxes for $\Sigma$ HBCDDs, $\Sigma$ NHFRs and $\Sigma$ MeO-BDEs in Bizerte city at the two seasons and for the whole sampling period (September 2015 to February 2016). Boxes represent the interquartile range, bound by the 75 th and 25 th percentile. Line and cross markers indicate medians and averages, respectively, whereas error bars show minimum and maximum dry deposition fluxes. 


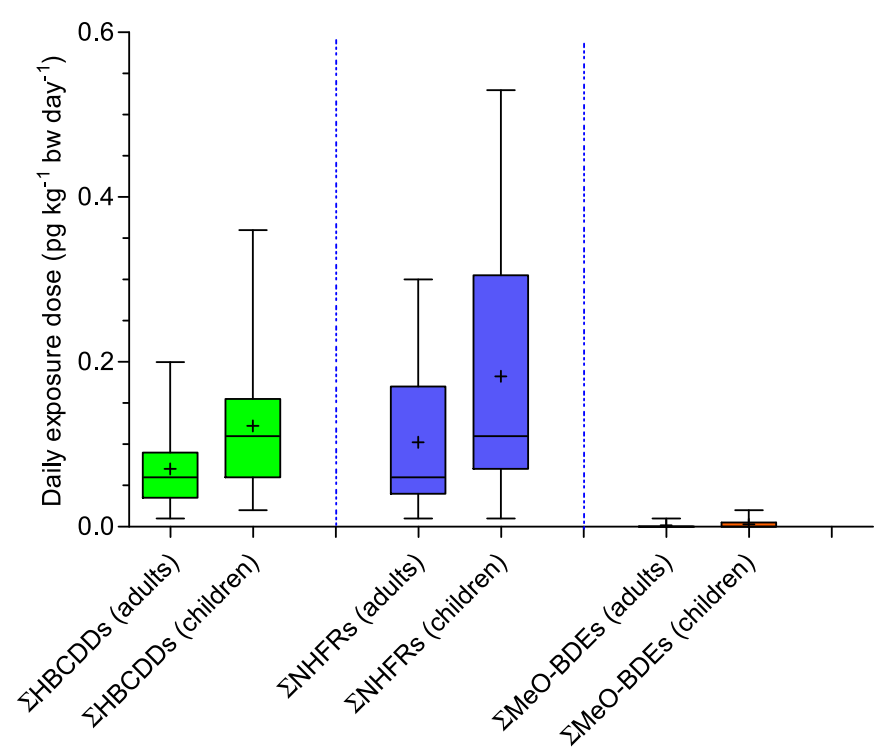

Fig. 6. Estimated daily exposure dose (DEDs) of adults and children to particlebound HBCDDs, NHFRs and MeO-BDEs via inhalation (ng $\mathrm{kg}^{-1}$ bw day ${ }^{-1}$ ). Boxes represent the interquartile range, bound by the 75 th and 25 th percentiles. Line and cross markers indicate medians and averages, respectively, whereas error bars show minimum and maximum daily exposure dose.

different particle-bound concentrations of HBCDDs and different $\mathrm{V}_{\mathrm{d}}$ values used for the estimation. Xie et al. (2011) reported for the HBB a dry deposition flux of $0.5 \mathrm{pg} \mathrm{m}^{-2} \mathrm{day}^{-1}$ (median value) in atmosphere of the Atlantic and the Southern Ocean, which was lower than that in the present study (median value of $12.49 \mathrm{pg} \mathrm{m}^{-2}$ day $^{-1}$ ). Dry deposition flux of DBDPE (mean of $65.25 \mathrm{pg} \mathrm{m}^{-2}$ day $^{-1}$ ) in Bizerte city was significantly lower than those measured in rural sites of Southern China (mean of $850 \mathrm{ng} \mathrm{m}^{-2} \mathrm{yr}^{-1}$ ) (Tian et al., 2011). The total dry deposition fluxes of DPs were in the range of $28.32-485.22 \mathrm{pg} \mathrm{m}^{-2} \mathrm{day}^{-1}$, with an average value of $178.80 \pm 149.30 \mathrm{pg} \mathrm{m}^{-2}$ day $^{-1}$, which is close to those observed by Okonski et al. (2014) in central Brno, Czech Republic (mean of $0.07 \mathrm{ng} \mathrm{m}^{-2}$ day $^{-1}$ ), but significantly lower than that detected in urban areas of Southern China (14.5-83.77 $\mathrm{ng} \mathrm{m}^{-2}$ day $^{-1}$ ) (Tian et al., 2011; Wu et al., 2017). Additionally, anti-DP was usually the less abundant isomer, contributing to $43 \%$ of the total DP deposition fluxes, suggesting that the anti-isomer is less persistent in the atmosphere than the syn-isomer. Considering the surface of the Bizerte Lagoon as $1.28 \times 10^{8} \mathrm{~m}^{2}$ (Barhoumi et al., 2016), approximately $0.01 \mathrm{~kg} \mathrm{yr}^{-1}$ of $\Sigma$ HBCDDs/ $/$ NHFRs and $2.34 \times 10^{-4} \mathrm{~kg} \mathrm{yr}^{-1}$ of $\Sigma \mathrm{MeO}$ BDEs can be deposited to surface waters through atmospheric particles.

The human body can be exposed to FRs through various exposure pathways, of which breathing is thought to be important (Li et al., 2018). Therefore, the daily exposure doses of children and adults to particle-bound HFRs and MeO-BDEs via outdoor air inhalation were estimated and are summarised in Fig. 6 and Table S7. The mean DED values for HBCDDs, NHFRs and MeO-BDEs were $0.07,0.10$ and $0.002 \mathrm{pg} \mathrm{kg}^{-1} \mathrm{bw}$ day $^{-1}$ for adults, respectively, and $0.12,0.18$ and $0.003 \mathrm{pg} \mathrm{kg}^{-1} \mathrm{bw} \mathrm{day}^{-1}$ for children, respectively. When the estimated exposures of DBDPE and 2'-MeO-BDE-68 were compared with corresponding reference dose (RfD) (Ali et al., 2012), they were several orders of magnitude lower than the RfD for both children and adults (Table S7), indicating insignificant risk to local population. Limited data of DED are available in literature for particle-bound FRs. Reche et al. (2019) found DED values for adults ranging from $2 \times 10^{-4}-8 \times 10^{-4}$, and from nd- $9 \times 10^{-4} \mathrm{ng} \mathrm{kg}^{-1} \mathrm{bw} \mathrm{day}^{-1}$ for DP and DBDPE, respectively; which were 5-15 folds higher than the DED values reported here. It is worth noting that DED values were calculated based on outdoor sources only. However HFRs are known to have higher concentrations in indoor than outdoor environments (Melymuk et al., 2016). Therefore the estimated DED must be taken with caution.

\section{Conclusion}

This study provided valuable baseline data on the occurrence, potential sources and impacts of HBCDDs, NHFRs and MeO-BDEs in a North African coastal city (Bizerte). Nine compounds ( $\alpha$-HBCDD, $\beta$ HBCDD, $\gamma$-HBCDD, HBB, DBDPE, syn-DP, anti-DP, 2'-MeO-BDE-68 and 6-MeO-BDE-47) were detected in all of the air samples. Tunisia does not manufacture FRs, therefore, their occurrence may have come from imported FR-containing products, which end up in landfills after their utilisation. Wind sector and air mass backward trajectories suggested that the sources of most FRs were mainly originated from local emissions. No obvious autumn/winter variations were observed for most of the compounds and the estimated DED indicating insignificant risk to local population as a result of their exposure to these pollutants through inhalation. Further research is needed to elucidate precisely the potential sources and impacts of these new organic contaminants in the study area.

\section{CRediT author statement}

Badreddine Barhoumi: Conceptualization, Methodology, WritingOriginal draft preparation, Writing-Reviewing and Editing; Marc Tedetti: Writing-Reviewing and Editing, finalizing the paper content; Andrea Peris and Òscar Aznar-Alemany: Data curation, Software and Methodology; Catherine Guigue: Initial data analysis; Soufiane Touil and Mohamed Ridha Driss: Supervision; Ethel Eljarrat: Funding acquisition, Methodology, Writing-Reviewing and Editing, Supervision and Validation.

\section{Declaration of competing interest}

All authors declare no competing financial interest.

\section{Acknowledgements}

This study was supported by the Institut de Recherche pour le Développement (IRD), through the International Joint Laboratory (LMI) "COSYS-Med", the Tunisian Ministry of Higher Education and Scientific Research, the PACA region "Particule" project, the IRD-MIO Action Sud "AEROBIZ" project and the Generalitat de Catalunya (Consolidated Research Group Water and Soil Quality Unit 2017). P. Raimbault (MIO) is acknowledged for $\mathrm{OC}$ and $\mathrm{ON}$ analyses. We are grateful to two anonymous Reviewers for their relevant comments on the manuscript.

\section{References}

Abdallah, M.A., Harrad, S., Covaci, A., 2008. Hexabromocyclododecanes and tetrabromobisphenol-A in indoor air and dust in Birmingham, UK: implications for human exposure. Environ. Sci. Technol. 42, 6855-6861.

Abdelouahab, N., AinMelk, Y., Takser, L., 2011. Polybrominated diphenyl ethers and sperm quality. Reprod. Toxicol. 31 (4), 546-550.

Alaee, M., Arias, P., Sjodin, A., Bergman, A., 2003. An overview of commercially used brominated flame retardants, their applications, their use patterns in different countries/regions and possible modes of release. Environ. Int. 29, 683-689.

Ali, N., Dirtu, A.C., Van den Eede, N., Goosey, E., Harrad, S., Neels, H., Mannetje, A.,

Coakley, J., Douwes, J., Covaci, A., 2012. Occurrence of alternative flame retardants in indoor dust from New Zealand: indoor sources and human exposure assessment. Chemosphere 88, 1276-1282.

Ali, N., Eqani, S.A.M.A.S., Ismail, I.M.I., Malarvannan, G., Kadi, M.W., Albar, H.M.S., Rehan, M., Covaci, A., 2016. Brominated and organophosphate flame retardants in indoor dust of Jeddah, Kingdom of Saudi Arabia: implications for human exposure. Sci. Total Environ. 569-570, 269-277. 
Arinaitwe, K., Muir, D.C.G., Kiremire, B.T., Fellin, P., Li, H., Teixeira, C., 2014. Polybrominated diphenyl ethers and alternative flame retardants in air and precipitation samples from the northern lake victoria region, east Africa. Environ. Sci. Technol. 48, 1458-1466.

Aznar-Alemany, O., Yang, X., Alonso, M.B., Costa, E.S., Torres, J.P.M., Malm, O., Eljarrat, E., Barceló, D., 2019a. Preliminary study of long-range transport of halogenated flame retardants using Antarctic marine mammals. Sci. Total Environ. 650, 1889-1897.

Aznar-Alemany, Ò., Sala, B., Plön, S., Bouwman, H., Barceló, D., Eljarrat, E., 2019b. Halogenated and organophosphorus flame retardants in cetaceans from the southwestern Indian Ocean. Chemosphere 226, 791-799.

Baldé, C.P., Wang, F., Kuehr, R., Huisman, J., 2014. The Global E-Waste Monitor - 2014: Quantities, Flows and Resources. United Nations University, Bonn, Germany.

Barhoumi, B., El Megdiche, Y., Clerandeau, C., Ben Ameur, W., Mekni, S., Bouabdallah, S., Derouiche, A., Touil, S., Cachot, J., Driss, M.R., 2016. Occurrence of polycyclic aromatic hydrocarbons (PAHs) in mussel (Mytilus galloprovincialis) and eel (Anguilla anguilla) from Bizerte lagoon, Tunisia, and associated human health risk assessment. Continent. Shelf Res. 124, 104-116.

Barhoumi, B., Castro-Jimenez, J., Guigue, C., Goutx, M., Sempere, R., Derouiche, A., Achour, A., Touil, S., Driss, M.R., Tedetti, M., 2018. Levels and risk assessment of hydrocarbons and organochlorines in aerosols from a North African coastal city (Bizerte, Tunisia). Environ. Pollut. 240, 422-431.

Barón, E., Giménez, J., Verborgh, P., Gauffier, P., de Stephanis, R., Eljarrat, E., Barceló, D., 2015. Bioaccumulation and biomagnification of classical flame retardants, related halogenated natural compounds and alternative flame retardants in three delphinids from Southern European waters. Environ. Pollut. 203, 107-115.

Ben Ameur, W., El Megdiche, Y., Eljarrat, E., Ben Hassine, S., Barhoumi, B., Trabelsi, S., Hammami, B., Barcelo, D., Driss, M.R., 2013. Organochlorine and organobromine compounds in a benthic fish (Solea solea) from Bizerte Lagoon (northern Tunisia): implications for human exposure. Ecotoxicol. Environ. Saf. 88, 55-64.

Bidleman, T.F., Agosta, K., Andersson, A., Haglund, P., Liljelind, P., Hegmans, A., Jantunen, L.M., Nygren, O., Poole, J., Ripszam, M., Tysklind, M., 2016. Sea-air exchange of bromoanisoles and methoxylated bromodiphenyl ethers in the Northern Baltic. Mar. Pollut. Bull. 112, 58-64.

Castro-Jiménez, J., Barhoumi, B., Paluselli, A., Tedetti, M., Jimenez, B., Munoz-Arnanz J., Wortham, H., Driss, M.R., Sempéré, R., 2017. Occurrence, loading, and exposure of atmospheric particle-bound POPs at the African and European edges of the western Mediterranean Sea. Environ. Sci. Technol. 51, 13180-13189.

Castro-Jiménez, J., Sempéré, R., 2018. Atmospheric particle-bound organophosphate ester flame retardants and plasticizers in a North African Mediterranean coastal city (Bizerte, Tunisia). Sci. Total Environ. 642, 383-393.

Chen, Y., Chen, Y.J., Zhang, Y., Li, R., Chen, W., Yan, S.C., Qi, Z., Chen, Z.F., Cai, Z., 2019. Determination of HFRs and OPFRs in $\mathrm{PM}_{2.5}$ by ultrasonic-assisted extraction combined with multi-segment column purification and GC-MS/MS. Talanta 194, 320-328.

Covaci, A., Gerecke, A.C., Law, R.J., Voorspoels, S., Kohler, M., Heeb, N.V., Leslie, H., Allchin, C.R., de Boer, J., 2006. Hexabromocyclododecanes (HBCDs) in the environment and humans: a review. Environ. Sci. Technol. 40, 3679-3688.

Covaci, A., Harrad, S., Abdallah, M.A.E., Ali, N., Law, R.J., Herzke, D., de Wit, C.A., 2011. Novel brominated flame retardants: a review of their analysis, environmental fate and behaviour. Environ. Int. 37, 532-556.

Dachs, J., Lohmann, R., Ockenden, W.A., Méjanelle, L., Eisenreich, S.J., Jones, K.C., 2002. Oceanic biogeochemical controls on global dynamics of persistent organic pollutants. Environ. Sci. Technol. 36, 4229-4237.

Dahlberg, K.D., Lindberg, V., Larsson, L.C., Bergman, A., Asplund, L., 2016. Hydroxylated and methoxylated polybrominated diphenyl ethers in long-tailed ducks (Clangula hyemalis) and theirmain food, Baltic blue mussels (Mytilus trossulus $\times$ Mytilus edulis). Chemosphere 144, 1475-1483.

Demirtepe, H., Imamoglu, I., 2019. Degradation of decabromodiphenyl ether (BDE-209) in microcosms mimicking sediment environment subjected to comparative bioremediation strategies. J. Environ. Manag. 233, 120-130.

Deng, W.-J., Li, N., Wu, R., Richard, W.K.S., Wang, Z., Ho, W., 2018. Phosphorus flame retardants and Bisphenol $\mathrm{A}$ in indoor dust and $\mathrm{PM}_{2.5}$ in kindergartens and primary schools in Hong Kong. Environ. Pollut. 235, 365-371.

Drage, D.S., Newton, S., de Wit, C.A., Harrad, S., 2016. Concentrations of legacy and emerging flame retardants in air and soil on a transect in the UK West Midlands. Chemosphere 148, 195-203.

El Megdiche, Y., Ben Ameur, W., Hammami, B., Ben Hassine, S., Barhoumi, B., Touil, S., Driss, M.R., Eljarrat, E., Barceló, D., 2017. Anthropogenic (PBDE) and naturallyproduced (MeO-PBDE) brominated compound levels in Bizerte Lagoon clams (Ruditapes decussatus): levels and human health risk assessment. Mar. Pollut. Bull. $125,176-185$.

Grami, B., Niquil, N., Sakka Hlaili, A., Gosselin, M., Hamel, D., Hadj Mabrouk, H., 2008. The plankton food web of the Bizerte Lagoon (South-western-Mediterranean): II. Carbon steady-state modelling using inverse analysis. Estuar. Coast Shelf Sci. 79 $101-113$.

Guerra, P., De La Cal, A., Marsh, G., Eljarrat, E., Barceló, D., 2009. Transfer of hexabromocyclododecane from industrial effluents to sediments and biota: case study in Cinca river (Spain). J. Hydrol. 369, 360-367.

He, Y., Murphy, M.B., Yu, R.M.K., Lam, M.H.W., Hecker, M., Giesy, J.P., Wu, R.S.S., Lam, P.K.S., 2008. Effects of 20 PBDE metabolites on steroidogenesis in the H295R cell line. Toxicol. Lett. 17, 230-238.

Hoh, E., Hites, R.A., 2005. Brominated flame retardants in the atmosphere of the eastcentral United States. Environ. Sci. Technol. 39, 7794-7802.

Hoh, E., Zhu, L., Hites, R.A., 2006. Dechlorane plus, a chlorinated flame retardant, in the Great Lakes. Environ. Sci. Technol. 40, 1184-1189.
Hu, J., Jin, J., Wang, Y., Ma, Z., Zheng, W., 2011. Levels of polybrominated diphenyl ethers and hexabromocyclododecane in the atmosphere and tree bark from Beijing, China. Chemosphere 84, 355-360.

Jo, H., Son, M.H., Seo, S.H., Chang, Y.S., 2017. Matrix-specific distribution and diastereomeric profiles of hexabromocyclododecane (HBCD) in a multimedia environment: air, soil, sludge, sediment, and fish. Environ. Pollut. 226, 515-522.

Kukučka, P., Vojta, Sr., Prokeš, R., Audy, O., Kohoutek, J., Klánová, J., 2013. BFRs Distribution in Air of Selected Indoor Environments from the Czech Republic. Platform Presentation, Sixth International Symposium on Flame Retardants, San Francisco.

Katima, Z., Okonkwo, J.O., Daso, A.P., 2017. A review of brominated flame retardants in the environment with emphasis on atmospheric levels, knowledge and information gaps in the African continent. Atmos. Pollut. REs. 8, 767-780.

Khairy, M.A., Lohmann, R., 2018. Selected organohalogenated flame retardants in Egyptian indoor and outdoor environments: levels, sources and implications for human exposure. Sci. Total Environ. 633, 1536-1548.

Kierkegaard, A., Bjorklund, J., Friden, U., 2004. Identification of the flameretardant decabromodiphenyl ethane in the environment. Environ. Sci. Technol. 38, 3247-3253.

Kim, U.J., Yen, N.T.H., Oh, J.E., 2014. Hydroxylated, methoxylated, and parent polybrominated diphenyl ethers (PBDEs) in the Inland environment, Korea, and potential OHand MeO-BDE source. Environ. Sci. Technol. 48, 7245-7253.

Koppen, R., Becker, R., Jung, C., Nehls, I., 2008. On the thermally induced isomerisation of hexabromocyclododecane stereoisomers. Chemosphere 71, 656-662.

Kurt-Karakus, P., Alegria, H., Jantunen, L., Birgul, A., Topcu, A., Jones, K.C., Turgut, C., 2017. Polybrominated diphenyl ethers (PBDEs) and alternative flame retardants (NFRs) in indoor and outdoor air and indoor dust from Istanbul-Turkey: levels and an assessment of human exposure. Atmos. Poll. Res. 8, 801-815.

Laakso, L., Gronholm, T., Kulmala, L., Haapanala, S., Hirsikko, A., Lovejoy, E.R., Kazil, J., Kurten, T., Boy, M., Nilsson, E.D., 2007. Hot-air balloon as a platform for boundary layer profile measurements during particle formation. Boreal Eviron. Res. 12, 279-294.

Lassen, C., Løkke, S., Andersen, L.I., 1999. Brominated Flame Retardants Substance Flow Analysis and Assessment of Alternatives. Danish Environmental Protection Agency, Denmark.

Li, H., Mo, L., Yu, Z., Sheng, G., Fu, J., 2012. Levels, isomer profiles and chiral signatures of particle-bound hexabromocyclododecanes in ambient air around Shanghai, China. Environ. Pollut. 165, 140-146.

Li, Q., Yang, K., Li, K., Liu, X., Chen, D., Li, J., Zhang, G., 2017. New halogenated flame retardants in the atmosphere of nine urban areas in China: pollution characteristics, source analysis and variation trends. Environ. Pollut. 224, 679-688.

Li, Y., Zhu, X., Wang, L., Gao, Y., Chen, J., Wang, W., Dong, X., Li, X., 2018. Levels and gas-particle partitioning of hexabromocyclododecanes in the urban air of Dalian, China. Environ. Sci. Pollut. Res. 25, 27514-27523.

Liu, D., Lin, T., Shen, K., Li, J., Yu, Z., Zhang, G., 2016. Occurrence and concentrations of halogenated flame retardants in the atmospheric fine particles in Chinese cities. Environ. Sci. Technol. 50, 9846-9854.

Liu, X., Bing, H., Chen, Y., Li, J., Wu, Y., Zhang, G., 2017. Brominated flame retardants and dechlorane plus on a remote high mountain of the eastern Tibetan Plateau: implications for regional sources and environmental behaviours. Environ. Geochem. Health 1-11.

Löfstrand, K., Liu, X., Lindqvist, D., Jensen, S., Asplund, L., 2011. Seasonal variations of hydroxylated and methoxylated brominated diphenyl ethers in blue mussels from the Baltic Sea. Chemosphere 84, 527-532.

Ma, Y., Salamova, A., Venier, M., Hites, R.A., 2013. Has the phase-out of PBDEs affected their atmospheric levels? Trends of PBDEs and their replacements in the Great Lakes atmosphere. Environ. Sci. Technol. 47, 11457-11464.

Malmvarn, A., Marsh, G., Kautsky, L., Athanasiadou, M., Bergman, Å., Asplund, L., 2005. Hydroxylated and methoxylated brominated diphenyl ethers in the red algae Ceramium tenuicorne and blue mussels from the Baltic Sea. Environ. Sci. Technol. 39, 2990-2997.

Masiol, M., Formenton, G., Pasqualetto, A., Pavoni, B., 2013. Seasonal trends and spatia variations of PM10-bounded polycyclic aromatic hydrocarbons in Veneto Region, Northeast Italy. Atmos. Environ. 79, 811-821.

Meire, R.O., Lee, S.C., Yao, Y., Targino, A.C., Torres, J.P.M., Harner, T., 2012. Seasonal and altitudinal variations of legacy and current-use pesticides in the Brazilian tropical and subtropical mountains. Atmos. Environ. 59, 108-116.

Mekni, S., Barhoumi, B., Aznar-Alemany, Ò., Touil, S., Driss, M.R., Barceló, D., Eljarrat, E., 2019. Occurrence of halogenated flame retardants in sediments and sea urchins (Paracentrotus lividus) from a North African Mediterranean coastal lagoon (Bizerte, Tunisia). Sci. Total Environ. 654, 1316-1325.

Melymuk, L., Bohlin-Nizzetto, P., Kukucka, P., Vojta, S., Kalina, K., Cupr, P., Klanova, J., 2016. Seasonality and indoor/outdoor relationships of flame retardants and PCBs in residential air. Environ. Pollut. 218, 392-401.

Möller, A., Xie, Z.Y., Sturm, R., Ebinghaus, R., 2010. Large-scale distribution of dechlorane plus in air and seawater from the Arctic to Antarctica. Environ. Sci. Technol. 44, 8977-8982.

Morf, L.S., Buser, A.M., Taverna, R., Bader, H.-P., Scheidegger, R., 2008. Dynamic substance flow analysis as a valuable risk evaluation tool: a case study for brominated flame retardants as an example of potential endocrine disrupters. Chimia 62, 424-431.

Newton, S., Sellstrom, U., de Wit, C.A., 2015. Emerging flame retardants, PBDEs, and HBCDDs in indoor and outdoor media in Stockholm, Sweden. Environ. Sci. Technol. 49, 2912-2920.

Nomiyama, K., Uchiyama, Y., Horiuchi, S., Eguchi, A., Mizukawa, H., Hirata, S.H., Shinohara, R., Tanabe, S., 2011. Organohalogen compounds and their metabolites in 
the blood of Japanese amberjack (Seriola quinqueradiata) and scalloped hammerhead shark (Sphyrna lewini) from Japanese coastal waters. Chemosphere 85, 315-321.

Okonski, K., Degrendele, C., Melymuk, L., Landlova, L., Kukucka, P., Vojta, S., Kohoutek, J., Cupr, P., Klanova, J., 2014. Particle size distribution of halogenated flame retardants and implications for atmospheric deposition and transport. Environ. Sci. Technol. 48, 14426-14434.

Pei, J.C., 2014. A Dissertation Submitted to Shanghai University for the Degree of Master in Engineering. Shanghai University, Shanghai.

Qiu, X., Marvin, C.H., Hites, R.A., 2007. Dechlorane Plus and other flame retardants in a sediment core from Lake Ontario. Environ. Sci. Technol. 41, 6014-6019.

Raff, J.D., Hites, R.A., 2007. Deposition versus photochemical removal of PBDEs from lake superior air. Environ. Sci. Technol. 41, 6725-6731.

Raimbault, P., Garcia, N., Cerrutti, F., 2008. Distribution of inorganic and organic nutrients in the South Pacific Ocean. Evidence for long-term accumulation of organic matter in nitrogen-depleted waters. Biogeosciences 5, 281-298.

Rauert, C., Schuster, J.K., Eng, A., Harner, T., 2018. Global atmospheric concentrations of brominated and chlorinated flame retardants and organophosphate esters. Environ. Sci. Technol. 52, 2777-2789.

Reche, C., Viana, M., Querol, X., Corcellas, C., Barceló, D., Eljarrat, E., 2019. Particlephase concentrations and sources of legacy and novel flame retardants in outdoor and indoor environments across Spain. Sci. Total Environ. 649, 1541-1552.

Ren, N., Sverko, E., Li, Y.F., Zhang, Z., Harner, T., Wang, D., Wan, X., McCarry, B.E., 2008. Levels and isomer profiles of dechlorane plus in Chinese air. Environ. Sci. Technol. 42, 6476-6480.

Renner, R., 2004. Government Watch: in US, flame retardants will be voluntarily phased out. Environ. Sci. Technol. 38, 14a.

Robinson, B.H., 2009. E-waste: an assessment of global production and environmental impacts. Sci. Total Environ. 408, 183-191.

Routti, H., Letcher, R.J., Chu, S., Van Bavel, B., Gabrielsen, G.W., 2009. Polybrominated diphenyl ethers and their hydroxylated analogues in ringed seals (Phoca hispida) from Svalbard and the Baltic Sea. Environ. Sci. Technol. 43, 3494-3499.

Saini, A., Clarke, J., Jariyasopit, N., Rauert, C., Schuster, J.K., Halappanavar, S., Evans, G.J., Su, Y., Harner, T., 2019. Flame retardants in urban air: a case study in Toronto targeting distinct source sectors. Environ. Pollut. 247, 89-97.

Salamova, A., Hites, R.A., 2011. Discontinued and alternative brominated flame retardants in the atmosphere and precipitation from the great lakes basin. Environ. Sci. Technol. 45, 8698-8706.

Salamova, A., Hermanson, M.H., Hites, R.A., 2014. Organophosphate and halogenated flame retardants in atmospheric particles from a European Arctic site. Environ. Sci. Technol. 48, 6133-6140.

Schluep, M., Manhart, A., Osibanjo, O., Rochat, D., Isarin, N., Mueller, E., 2011. Where Are WEEE in Africa. Findings from the Basel Convention E-Waste Africa Programme Secretariat of the Basel Convention 2011.

Shunthirasingham, C., Alexandrou, N., Brice, K.A., Dryfhout-Clark, H., Su, K., Shin, C., Park, R., Pajda, A., Noronha, R., Hung, H., 2018. Temporal trends of halogenated flame retardants in the atmosphere of the Canadian Great Lakes Basin (2005-2014). Environ. Sci. Process. Impact 20, 469-479.

Tasdemir, Y., Holsen, T.M., 2005. Measurement of particle phase dry deposition fluxes of polychlorinated biphenyls (PCBs) with a water surface sampler. Atmos. Environ. 39, 1845-1854.

Tian, M., Chen, S.J., Wang, J., Shi, T., Luo, X.J., Mai, B.X., 2011. Atmospheric deposition of halogenated flame retardants at urban, e-waste, and rural locations in southern
China. Environ. Sci. Technol. 45, 4696-4701.

UNEP, 2015. Drafted Guidance for the Inventory, Identification and Substitution of Hexabromocyclododecane (HBCD).

USEPA, 2011. Exposure Factors Handbook. U.S. Environmental Protection Agency (USEPA), Washington, DC EPA/600/R-09/052F.

Venier, M., Hites, R.A., 2008. Flame retardants in the atmosphere near the Great Lakes. Environ. Sci. Technol. 42, 4745-4751.

Vorkamp, K., Bossi, R., Riget, F.F., Skov, H., Sonne, C., Dietz, R., 2015. Novel brominated flame retardants and dechlorane plus in Greenland air and biota. Environ. Pollut. 196, 284-291.

Wang, D.G., Yang, M., Qi, H., Sverko, E., Ma, W.L., Li, Y.F., Alaee, M., Reiner, E.J., Shen, L., 2010. An Asia-specific source of dechlorane plus: concentration, isomer profiles, and other related compounds. Environ. Sci. Technol. 44, 6608-6613.

Wiseman, S.B., Wan, Y., Chang, H., Zhang, X., Hecker, M., Jones, P.D., Giesy, J.P., 2011. Polybrominated diphenyl ethers and their hydroxylated/methoxylated analogs: environmentalsources, metabolic relationships, and relative toxicities. Mar. Pollut. Bull. 63, 179-188.

Wu, X., Wang, Y., Hou, M., Luo, C., Zhao, H., Zhang, G., 2017. Atmospheric deposition of PBDEs and DPs in dongjiang river basin, south China. Environ. Sci. Pollut. Res. 24, 3882-3889.

Xie, Z., Moller, A., Ahrens, L., Sturm, R., Ebinghaus, R., 2011. Brominated flame retardants in seawater and atmosphere of the Atlantic and the Southern Ocean. Environ. Sci. Technol. 45, 1820-1826.

Yang, R.Q., Wei, H., Guo, J.H., McLeod, C., Li, A., Sturchio, N.C., 2011. Historically and currently used dechloranes in the sediments of the Great Lakes. Environ. Sci. Technol. 45, 5156-5163.

Yu, Z.Q., Chen, L.G., Mai, B.X., Wu, M.H., Sheng, G.Y., Fu, J.M., Peng, P.A., 2008. Diastereoisomer and enantiomer-specific profiles of hexabromocyclododecane in the atmosphere of an urban city in south China. Environ. Sci. Technol. 42, 3996-4001.

Yu, Z., Liao, R.E., Li, H., Mo, L., Zeng, X., Sheng, G., Fu, J., 2011. Particle-bound Dechlorane Plus and polybrominated diphenyl ethers in ambient air around Shanghai, China. Environ. Pollut. 159, 2982-2988.

Yu, M., Liu, J., Wang, T., Sun, J., Liu, R., Jiang, G., 2013. Metabolites of 2,4,4'-tribrominated diphenyl ether (BDE-28) in pumpkin after in vivo and in vitro exposure. Environ. Sci. Technol. 47, 13494-13501.

Zeng, X., Simonich, S.L.M., Robrock, K.R., Korytar, P., Alvarez- Cohen, L., Barofsky, D.F. 2008. Development and validation of a congener-specific photodegradation model for polybrominated diphenyl ethers. Environ. Toxicol. Chem. 27, 2427-2435.

Zhang, X., Sühring, R., Serodio, D., Bonnell, M., Sundin, N., Diamond, M.L., 2016. Nove flame retardants: estimating the physical-chemical properties and environmental fate of 94 halogenated and organophosphate PBDE replacements. Chemosphere 144, 2401-2407.

Zhang, W., Wang, P., Zhu, Y., Yang, R., Li, Y., Wang, D., Matsiko, J., Han, X., Zhao, J., Zhang, Q., Zhang, J., Jiang, G., 2019. Brominated flame retardants in atmospheric fine particles in the Beijing-Tianjin-Hebei region, China: spatial and temporal distribution and human exposure assessment. Ecotox. Environ. Safe. 171, 181-189.

Zhao, Y.F., Ma, J., Qiu, X.H., Lin, Y., Yang, Q.Y., Zhu, T., 2013. Gridded field observations of polybrominated diphenyl ethers and decabromodiphenyl ethane in the atmosphere of North China. Environ. Sci. Technol. 47, 8123-8129.

Zhu, Y.S., Yang, W.D., Li, X.W., Ni, H.G., Zeng, H., 2018. Airborne particle-bound brominated flame retardants: levels, size distribution and indoor-outdoor exchange. Environ. Pollut. 233, 1104-1112. 